\title{
Pott's Paraplegia: An account of the Treatment of 89 Consecutive Patients
}

\author{
P. R. M. Pattisson, O.B.E., M.A., M.B., B.Chir.
}

Formerly Physician in-charge, Bone E Foint Tuberculosis Wing, National Hospital, Masan, Korea

\section{Summary}

The results of the treatment of 89 consecutive cases of Pott's paraplegia admitted to care in Korea are reported. Eighty-five patients were treated conservatively. Four patients underwent costo-transversectomy, three of them in the later stages of treatment without apparent benefit. All patients were followed-up for more than one year, $22(25 \%)$ of them for five years or more.

75 patients $(84 \%)$ recovered sufficiently to walk unaided. 74 patients $(83 \%)$ returned to normal life and full activity. 64 of these $(72 \%)$ were neurologically and functionally completely normal and, at the end of follow-up, the other ten $(11 \%)$ had minimal persistent neurological signs not affecting life and activity. 54 patients $(61 \%)$ spent less than six months in hospital and $56(63 \%)$ returned to normal activity within one year of the start of treatment. There were two deaths. 41 patients $(46 \%)$ deteriorated neurologically during the first two months of treatment, but 37 of these recovered completely.

The place of chemotherapy as the basis of the treatment of Pott's disease is emphasised. A comparison is made with the published results of other series. The place of operative intervention is discussed and it is argued that the case for urgent early surgical intervention in the treatment of Pott's paraplegia may have been overstated. Key words: Spinal tuberculosis; Paraplegia; Chemotherapy.

\section{Introduction}

Between October 1975 and October 1981, 724 new patients suffering from tuberculosis of the spinal column were treated on an in- or out-patient basis by the author at the unit for the care of bone and joint tuberculosis attached to the National Hospital for Tuberculosis in Masan, Republic of Korea. Eighty-nine $(12 \%)$ of these either presented with paraplegia or developed paraplegia during the course of their treatment. No patient in the present series was lost to follow-up during the period reported.

The British Medical Research Council Working Party studies into spinal tuberculosis in patients without paraplegia have shown that, in circumstances Address for correspondence: Haven of Hope Hospital, Junk Bay, Kowloon, Hong Kong. 
where medical, surgical and financial resources are limited, 'reliance should be placed with confidence on ambulant out-patient chemotherapy' as an acceptable alternative to chemotherapy coupled with operative treatment. (Griffiths, 1979, Medical Research Council 1973, 1976, 1978) Paraplegic patients were excluded from the Working Party studies, but the series of paraplegics reported here were treated conservatively (with four exceptions) because the unit at Masan had no operating theatre and opportunities for surgical referral were limited. Surgical treatment on a private basis could be obtained only if the cost was within the financial means of the patient. It hardly ever was. Thus, of necessity, the treatment of the patients in this series, with four exceptions, was conservative. Four patients underwent costo-transversectomy, one in the first month of treatment and the other three in the later stages of management. In the opinion of the surgeon concerned and of the author, in none of these cases (with the possible exception of the first) did the operation have any effect for better or worse upon the subsequent progress of the patient concerned.

Radiological facilities provided by the National Hospital were limited to plain $\mathrm{X}$-rays of bones and lungs. Myelography was not available and lumbar puncture was not performed. Facilities for reliable bacteriology were not available.

\section{Materials and Methods}

For the purpose of this study Pott's paraplegia was defined as impairment of spinal cord function severe enough to prevent walking unaided across the room (5 metres) due to spinal tuberculosis. Patients with pyramidal signs but whose disability did not prevent unaided walking across a room of this size were not included. Those who could not cross the room unaided included those who required one or more sticks, crutches or a walking frame, as well as those who could not cross the room at all even with such aids.

\section{Preliminary Investigations}

All patients attending the unit for bone and joint tuberculosis in Masan or the associated clinics and suspected of having tuberculosis of the spine, including those in the present report, were investigated as follows:

1. Full clinical and detailed neurological examination.

2. Antero-posterior and lateral radiographs of the spine.

3. Postero-anterior radiograph of the lungs.

4. Mantoux test.

5. Culture of sputum or pus for tubercle bacilla when available.

The clinical and radiological criteria for diagnosis of tuberculosis of the spine were the same as those employed in the Medical Research Council series (MRC 1973).

\section{Active and Healed Disease}

In the absence of evidence obtained at operation the distinction between active and healed disease can never be completely reliable. For the purpose of this study, apparently healed disease was identified by the following criteria:

1. The presence of a lesion, at the time when first seen, which had already healed 
by bony fusion of the affected vertebral bodies and in which uniformity of bone density and clear delineation of the affected parts of the highest and lowest diseased bodies was radiologically demonstrable.

2. In doubtful cases where there was no evidence of increasing bone destruction in serial radiographs.

3. Where there was no evidence of increase in the size of the shadow of any paravertebral abscess shown in serial radiographs.

4. The absence of fluid pus in any abscess available for evacuation.

In the MRC Working Party's studies, the diagnosis of spinal tuberculosis was considered by the independent assessor as incorrect in 18 of a series of 350 patients; an error of the order of $5 \%$. There seems no reason to believe that in this series of paraplegics the accuracy of the diagnosis of the causative disease was any less. Indeed, because of the greater severity of the disease it could reasonably be expected to be greater.

Details of clinical data at the time of presentation are shown in Table 1, age, sex, duration of symptoms of spinal disease and complications in Table 2.

Table 1 Neurological and Functional Status on presentation

\begin{tabular}{|c|c|c|c|}
\hline Grade & Description & $\begin{array}{l}\text { No. of } \\
\text { Patients }\end{array}$ & $\%$ \\
\hline$\star_{0}$ & Normal & 10 & 11 \\
\hline$\star \mathbf{I}$ & $\begin{array}{l}\text { Pyramidal signs present no motor or sensory impairment, able to } \\
\text { walk unaided }\end{array}$ & 10 & 11 \\
\hline IIa) & Incomplete motor loss, no sensory impairment, able to walk with help & 24 & 27 \\
\hline IIb) & Incomplete motor loss, no sensory impairment, unable to walk & 6 & 7 \\
\hline III & Complete motor loss, no sensory impairment unable to walk & 17 & 19 \\
\hline IV & Complete motor loss, sensation impaired or lost, unable to walk & 13 & 15 \\
\hline V & $\begin{array}{l}\text { Complete motor loss, severe or total sensory loss, loss of sphincter } \\
\text { control and/or muscles spasms }\end{array}$ & 9 & 10 \\
\hline Total & & 89 & 100 \\
\hline
\end{tabular}

^Note: These patients all subsequently developed paraparesis of at least Grade II severity.

A sinus was present in the left iliac fossa of one patient. This was due to a separate focus of lumbar disease while the paraplegia was caused by a high thoracic lesion. A palpable psoas abscess was present in one patient. Active pulmonary tuberculosis was present in 25 patients $(28 \%$ ). Tuberculous involvement of the hip was found in three patients and of the kidney and cervical glands in one each.

Activity level and extent of the vertebral disease can be seen in Table 3 .

The old classification of Pott's paraplegia according to the length of history of the bony disease at the time of onset of the paralysis is not used in this paper. It is less useful than the classification introduced by the Hong Kong surgeons (Hodgson and Yau, 1964) into paraplegia arising in active vertebral disease, however late, and that starting after the bony disease has healed, however early. In the present series ten patients $(11 \%)$ were considered to have paraplegia that had arisen in the presence of healed vertebral disease and $79(89 \%)$ to have paraplegia in the presence of active bony tuberculosis.

Duration of neurological symptoms have been summarised in Table 4.

Ten patients $(11 \%)$ had no neurological symptoms on presentation. These and ten others, whose neurological symptoms were confined to pyramidal signs at 
Table 2 Pretreatment Characteristics

\begin{tabular}{lcrr}
\hline & Characteristic & No. & $0^{\circ}$ \\
\hline Age (years) & under 5 & 16 & 18 \\
& $5-14$ & 16 & 18 \\
& $15-24$ & 22 & 25 \\
& $25-44$ & 26 & 29 \\
& 45 or more & 9 & 10 \\
Sex & Male & \\
& Female & 49 & 55 \\
& & 40 & 45 \\
Duration of Symptoms of spinal disease & & \\
& Less than 6 months & 30 & 34 \\
& $6-12$ months & 26 & 29 \\
& $1-4$ years & 15 & 17 \\
Sinus and/or clinically evident abscess present & 18 & 20 \\
Pressure sores present & 5 years or more & 2 & 2 \\
Retention of urine present & 7 & 8 \\
Other active tuberculous lesions present (including pulmonary) & 3 & 3 \\
Total patients & 30 & 34 \\
\hline
\end{tabular}

Table 3 Radiographic Characteristics on presentation

\begin{tabular}{lrr}
\hline \multicolumn{1}{c}{ Radiographic Characteristic } & No. & $\mathrm{o}_{\circ}{ }^{\circ}$ \\
\hline Disease apparently active & 79 & 89 \\
Disease apparently healed & 10 & 11 \\
Centre of bony lesion: & & \\
$\star$ Cervico-thoracic (CI-T1) & 7 & 8 \\
Upper-mid thoracic (T1-T6) & 29 & 32 \\
Mid-lower thoracic (T6-T12) & 46 & 52 \\
Thoraco-lumbar (T12-L5) & 7 & 8 \\
Number of vertebrae involved & 39 & 44 \\
2 & 19 & 21 \\
3 & 31 & 35 \\
4 or more & 72 & 81 \\
Mediastinal or psoas abscess shadow visible & 89 & 100 \\
Total patients & & \\
\hline
\end{tabular}

* There were no lesions confined to the cervical spine in this series.

Table 4 Duration of Neurological Symptoms at Presentation

\begin{tabular}{lcr}
\hline \multicolumn{1}{c}{ Duration } & No. of Patients & $\%$ \\
\hline Neurologically normal & 10 & 11 \\
Less than 1 month & 18 & 20 \\
1 month - & 23 & 26 \\
3 months - & 24 & 27 \\
6 months - & 6 & 7 \\
12 months or more & 8 & 9 \\
Total & 89 & 100 \\
\hline
\end{tabular}

^Note: These patients subsequently developed paraparesis of Grade II or more. 
presentation, all developed paraplegia of Grade II or more during treatment. This important group of 20 patients will be considered separately under progress and results. One patient, a seven-year old boy with disease of the lower cervical and upper thoracic spine, had a paresis of his left arm in addition to motor loss in both legs.

\section{Management}

\section{Chemotherapy}

All patients, including those with apparently healed disease, received two drugs orally. Streptomycin was not used. Thirty-six patients in the present series were admitted to the MRC study of the ambulant treatment of spinal tuberculosis by short-term chemotherapy. Some had presented without paraplegia and others with paraplegia were admitted in error. The drug regimen for these patients was determined by random allocation and the drugs were provided by the MRC. In the remaining patients drug regimens were determined by the availability of drugs and of money for their purchase. Each patient received INAH in combination with rifampicin, ethambutol or PAS, for periods ranging from six to 18 months. The number of patients receiving each regimen is listed in Table 5.

The dosages used were as in the MRC studies, namely rifampicin 10-20 mg per kilo of body weight daily to a maximum of $600 \mathrm{mg}$ per day; PAS 200-350 mg per kilo daily to a maximum of 10 gm per day; ethambutol $15-25 \mathrm{mg}$ per kilo daily to a maximum of $800 \mathrm{mg}$; INAH 6-30 mg per kilo daily to a maximum of $300 \mathrm{mg}$. In no case was any adverse effect observed.

Great care was taken to ensure continuity of drug taking and completion of treatment. All patients completed their course of chemotherapy, except one who died in the third month. Four patients defaulted on chemotherapy for periods totalling more than one month during the course of treatment (three for six weeks

Table 5 Chemotherapy regimens prescribed

\begin{tabular}{rcr}
\hline Basic Regimen & No. of Patients & Notes \\
\hline INAH plus Rifampicin: & 8 & Includes 3 patients with additional chemotherapy \\
6 months & 12 & Includes 3 patients with additional chemotherapy \\
9 months & 13 & Includes 1 patient with additional chemotherapy
\end{tabular}

INAH plus Ethambutol:

$\begin{array}{rrl}9 \text { months } & 3 & \\ 12 \text { months } & 3 & \\ 18 \text { months } & 15 & \text { Includes } 1 \text { patient with additional chemotherapy } \\ 9 \text { months } & 4 & \text { Includes } 1 \text { patient with additional chemotherapy } \\ 12 \text { months } & 6 & \\ 18 \text { months } & 25 & \text { Includes } 2 \text { patients with additional chemotherapy }\end{array}$

Total Patients 89

Notes: 1. With one exception courses of additional chemotherapy used only Rifampicin, Ethambutol or PAS in combination with INAH for periods ranging from 6 to 18 months.

2. In two of these patients further chemotherapy was prescribed for the treatment of pulmonary tuberculosis. In the other nine additional chemotherapy was given for the treatment of the spinal disease.

3. One patient whose paraplegia had still not resolved at the end of follow up had 18 months of INAH and PAS, with Rifampicin added for the last 12 months of this period. This was followed by 12 months of Pyrazinamide, Ethionamide and INAH. 
and one for ten weeks). This loss was subsequently restored by prolonging treatment accordingly.

\section{Hospital Admission}

It was our policy to admit paraplegic patients to hospital for the duration of their paraplegia. The 20 patients who developed paraplegia while already on outpatient ambulant chemotherapy were admitted to hospital. Five patients refused admission and were managed exclusively at home. None of these appeared to suffer ill effects from this.

Patients were nursed on ordinary firm beds. Frames or plaster beds were not used. Daily passive mobilisation of the lower limbs and exercises of the upper limbs were a routine. Particular attention was paid to skin care. Seven patients had pressure sores at the time of admission and three other patients developed pressure sores during treatment; all of these healed satisfactorily. Seven patients $(8 \%)$ had periods of retention of urine. Indwelling Foley catheters were used until recovery justified removal of the catheters. In no case did this period exceed three months.

The MRC studies demonstrated the effectiveness of ambulant chemotherapy in the treatment of spinal tuberculosis in the non-paraplegic patient (MRC 1973, 1976). Furthermore, they show the inability of six months enforced bedrest or nine months wearing of a plaster jacket to confer any additional benefit to the patient.

No attempt was made at any stage to enforce horizontal bedrest. Patients with early bony disease who were debilitated or had marked back pain, spent most of the day horizontal, but as soon as general factors allowed, patients were encouraged to sit up in bed or move around in a wheelchair for short periods. As soon as power began to return in the lower limbs, patients were encouraged to stand between parallel bars or in a walking frame for short periods. We did not detect in our patients the phenomenon reported elsewhere of paraparesis increasing when sitting up and becoming less when lying down (Hodgson, Yau and Kim, 1964). We know of no case in our series where early mobilisation appeared to cause exacerbation of the paraparesis or to have any other ill effect.

The interaction of patients among themselves was beneficial towards morale (Konstam \& Konstam 1958). This esprit de corps among the patients was important in eliciting their active cooperation in treatment, continuation of chemotherapy after returning home and confidence in the final outcome. The relationship of trust between staff and patients, developed in the atmosphere of a Christian hospital, contributed very largely to this.

Details of duration of in-patient care are shown in Table 6.

Patients who were recovering were usually discharged home as soon as they were reasonably safe and active on crutches. Those who did not recover fully were discharged home when they had ceased to improve functionally. In four cases hospital admission was extended for compassionate reasons for periods for up to two years. Four other patients were subsequently readmitted for periods ranging from three to eight months for physiotherapy and other rehabilitation. These were all patients with residual Grade 2a paraparesis, i.e. patients who were able to walk with help. 
Table 6 Duration of In-Patient Care

\begin{tabular}{lcr}
\hline Duration (months) & No. of Patients & $\%$ \\
\hline Never admitted to hospital & 5 & 6 \\
Less than 3 months & 13 & 15 \\
$3-$ & 37 & 41 \\
$6-$ & 22 & 25 \\
12 or more & 10 & 11 \\
Died & 2 & 2 \\
Total & 89 & 100 \\
\hline
\end{tabular}

Note: 1.54 patients $(61 \%)$ spent less than 6 months in hospital.

2. Of the two deaths, one patient died in the third month of admission and the other died at home in the eighteenth month from the start of treatment, having had eleven months of hospital admission.

\section{Surgical Intervention}

Eighty-five patients $(96 \%)$ were treated conservatively; four patients underwent costo-transversectomy. One had had two months of deteriorating neurological signs with active disease of T-7, 8 vertebrae. The surgeon's note was 'about 5 to $7 \mathrm{ml}$ of pus removed, not under pressure, no loose sequestrum, prognosis guarded.' Neurological recovery began about one month post-operatively. The other three patients, all male, all with originally active spinal disease and aged 3, 13 and 20 years respectively, had operations between 11 months and two years after the start of chemotherapy. In all three, the paraparesis was not improving and at the time of operation the bony disease was judged to be quiescent. One made a partial recovery to Grade IIa paraparesis beginning seven months after operation. There was no change in the other two patients during the period of follow-up.

The period of follow-up of patients in the present series varied between one and six years (Table 7). While the period of follow-up was less than three years in 35 patients $(39 \%)$, the MRC studies have shown that, given an adequate uninterrupted course of anti-tuberculous chemotherapy, the relapse rate in non-paralytic spinal tuberculosis is extremely small (MRC 1976, 1978). There were no defaulters during the period of follow-up.

Table 7 Duration of Follow-Up

\begin{tabular}{lcc}
\hline Duration (years) & No. & $\%$ \\
\hline $1-$ & 21 & 23 \\
$2-$ & 14 & 16 \\
$3-$ & 19 & 21 \\
$4-$ & 13 & 15 \\
5 or more & 22 & 25 \\
Total patients & 89 & 100 \\
\hline
\end{tabular}


Table 8 Status at the end of follow-up

\begin{tabular}{|c|c|c|c|c|c|c|c|c|}
\hline \multirow{2}{*}{$\begin{array}{l}\text { Status at end of } \\
\text { follow up }\end{array}$} & \multicolumn{7}{|c|}{ Duration of Neurological symptoms at presentation (months) } & \multirow{2}{*}{$\begin{array}{l}\% \text { of } \\
\text { totals }\end{array}$} \\
\hline & Normal & -1 & $1-$ & $3-$ & $6-$ & $12-$ & Totals & \\
\hline 0 & 9 & 13 & 19 & 19 & 4 & & 64 & 72 \\
\hline I & & 1 & 1 & 3 & 1 & 2 & $8^{\star}$ & 9 \\
\hline IIa & 1 & 3 & 1 & 1 & & 4 & $10 \dagger$ & 12 \\
\hline IIb & & & & & 1 & & 1 & 1 \\
\hline III & & & & & & 1 & 1 & 1 \\
\hline IV & & & 1 & & & & 1 & 1 \\
\hline V & & & 1 & & & 1 & 2 & 2 \\
\hline Dead $\star \star$ & & 1 & & 1 & & & 2 & 2 \\
\hline Totals & 10 & 18 & 23 & 24 & 6 & 8 & 89 & 100 \\
\hline
\end{tabular}

$\star 5$ with no functional disability.

$\dagger$ Includes 3 patients able to walk unaided.

Note: 75 patients $(84 \%)$ recovered sufficiently to walk unaided. All but one of these returned to normal life and full activity.

$\star \star$ directly attributable to Pott's paraplegia and its sequelae.

\section{Progress and Results}

The status of the 89 patients at the end of follow-up is shown in Table 8. Sixtyfour patients $(72 \%)$ were functionally and neurologically normal at the end of follow-up. Seventy-five patients $(84 \%)$ recovery sufficiently to walk unaided. All but one of these patients returned to normal life and full activity. Two patients died and five were left paralysed and unable to walk. The remaining seven patients $(8 \%)$ were left with varying degrees of disability but were able to walk with the assistance of crutches.

The following points are of particular interest in the progress of the patients during treatment.

\section{i) Initial deterioration}

Apart from the two patients who died, $41(46 \%)$ deteriorated both functionally and neurologically in the early stages of treatment. In 40 , this occurred in the first two months of treatment and all except six of these patients made a full recovery. Of the six patients in this group who did not proceed to full recovery, two were developing paraplegia in healed disease that was apparently unaffected by our treatment, two made a complete functional recovery, one was left with a slightly spastic gait but was fully active and one 22-year-old man described below was left with weakness of the right leg but was active and able to walk with a stick.

The remaining patient in this whole group of 41 was a two-year-old girl, neurologically normal at the time of registration who developed total motor paraplegia during the fifth month of treatment. This resolved within 30 days and she went on to an uneventful recovery.

\section{ii) Paraplegia arising during treatment}

Among the 41 patients whose condition deteriorated during the early stages of treatment there were 20 who developed paraplegia for the first time after the 
beginning of treatment. Ten of these were neurologically normal at the time of registration and ten had minor neurological impairment that did not prevent their walking unaided across a room 5 metres wide. Five of the six patients described above who did not make a full recovery, were among this group of 20. However, in only two was the condition at the end of follow-up worse than at the beginning of treatment. One of these had paraplegia in healed disease; the other, a man of 22 , had presented with five months' history of symptoms of spinal tuberculosis found to be affecting the bodies of T9 and 10 veretebrae. Radiological evidence of a small para-vertebral abscess was visible on both sides of the thoracic spine at that level. There was no neurological abnormality on presentation but he walked slowly and stiffly because of backache. Out-patient chemotherapy was initiated using $600 \mathrm{mg}$ of rifampicin and $300 \mathrm{mg}$ of INAH daily. Neurological signs developed during the first month of treatment and he was admitted to hospital. The neurological signs progressed to total motor paraplegia by the third month. Sensation and bladder and bowel sphincters were partially involved by the fourth month and this persisted to the sixth month. Over the next two months sphincter control, sensation and power returned slowly and by nine months he was walking with crutches. He was discharged home in the tenth month, after nine months in hospital. The spinal lesion progressed to healing and bony fusion. The patient continued to improve functionally until he could walk steadily with the aid of a stick. He was subsequently readmitted for a six-month period of physiotherapy and rehabilitation. When last seen, four years after the start of treatment, he was professionally and physically active, sometimes using a stick.

\section{iii) Recurrent paraplegia}

One patient, a 51-year-old man with a 35-year history indicative of tuberculosis of the thoraco-lumbar spine (T9-L3) had two separate episodes of paraplegia. On his first admission to hospital, he gave a four-month history of paraparesis (Grade IIb, partial motor loss and unable to walk). He was considered to have active disease. Treatment with $730 \mathrm{mg}$ of ethambutol and $300 \mathrm{mg}$ of INAH daily was initiated and continued to 18 months. The paralysis began to resolve in the first month of treatment and power was fully recovered within three months. The second episode began slowly, two and a half years after the completion of the first course of treatment. On this occasion, he was judged to have healed disease but treatment with $600 \mathrm{mg}$ of rifampicin and $300 \mathrm{mg}$ of INAH daily was initiated as a precaution. The paraparesis progressed to total motor paralysis (Grade III) during the first two months of retreatment but began to resolve again in the third month. By the sixth month of treatment he was neurologically normal, and remained so 18 months after the complete resolution of this second episode of paraplegia.

There were no other recurrences of paraplegia and no instances of reactivation of tuberculous spinal lesions in the present series.

\section{iv) Rupture of abscesses and resolution of paraplegia}

In two patients abscesses ruptured externally and in two patients mediastinal abscesses ruptured internally into lungs. 
In all four patients resolution of the paraplegia began within 48 hours of rupture of the para-vertebral abscess.

\section{Time for Recovery}

Table 9 shows the total duration of paraplegia in these patients. It will be seen that in $42(48 \%)$ paraplegia lasted less than three months. In another $27(30 \%)$ it lasted between three and six months. In four patients, paraplegia lasted between six and 12 months and only two patients with paraplegia lasting more than 12 months recovered enough to walk.

Table 10 shows the time taken for return to normal activity.

Table 9 Total Duration of Paraplegia

\begin{tabular}{lcr}
\hline Duration of Paraplegia (months) & No. of Patients & $\%$ \\
\hline Less than 1 month & 6 & 7 \\
$1-$ & 16 & 18 \\
$2-$ & 20 & 23 \\
$3-$ & 9 & 10 \\
$4-$ & 9 & 10 \\
$5-$ & 9 & 10 \\
$6-$ & 3 & 3 \\
$7-$ & 1 & 1 \\
$12-14$ & 2 & 2 \\
Persistent paraplegia & 12 & 14 \\
Died & 2 & 2 \\
Total patients & 89 & 100 \\
\hline
\end{tabular}

Note: 1. Total duration of paraplegia includes pretreatment period.

2. 75 patients $(84 \%)$ recovered sufficiently to walk unaided. All but one of those returned to normal life and full activity.

3. In 12 patients $(14 \%)$ paraplegia persisted at the end of follow up to the extent that they were unable to walk unaided. $7(8 \%)$ of these could walk with assistance.

Table 10 Duration of Incapacity for Normal Life and Full Activity from start of Treatment

\begin{tabular}{lcc}
\hline Duration (months) & No. & $\%$ \\
\hline Less than 6 months & 24 & 27 \\
$6-$ & 32 & 36 \\
12 or more & 18 & 20
\end{tabular}

Summary of residual disabilities at the end of follow up

Able to walk, but not fully active $\quad 8 \quad 9$

Unable to walk $\quad 5 \quad 6$

Died 22

$\begin{array}{lll}\text { Total } & 89 & 100\end{array}$

Note: 56 patients $(63 \%)$ returned to normal life and full activity within 12 months of the start of treatment. Altogether 74 patients $(83 \%)$ returned to normal life and full activity. 


\section{Discussion}

A detailed analysis of all the factors that could influence prognosis is not possible in a series of this size, but age of the patient, site of the lesion and extent of the bony disease did not appear to have a significant influence on the outcome.

Paraplegia in the presence of apparently healed bony disease undoubtedly carried a worse prognosis. Only two of the ten patients in this group made a full recovery.

Duration of paraplegia prior to treatment did not appear to affect the outcome significantly unless it had been present for over six months (see Table 8) and nearly all the patients in this group had apparently healed bony disease.

Neurological deterioration or the onset of paraplegia during treatment is commonly regarded as an ominous sign (Griffiths 1979) and an absolute indication for urgent operative decompression. (Kemp 1976, Martini 1979, Spillane 1973, Tuli 1976). In the present series 40 patients $(45 \%)$ developed paraplegia or showed neurological deterioration during the first two months of treatment. In all but four of these the neurological signs resolved completely within six months of their onset. The prognosis for that group of patients was no worse than that for the overall series.

Four of the key issues in the choice of treatment (British Medical Journal (Editorial) 1979) may be summarised as follows:

1. What is the place of chemotherapy in the overall management of the patient?

2. When, if ever, is chemotherapy alone, the treatment of choice in the patient with Pott's paraplegia?

3. How big a factor in the choice of treatment is time taken for recovery of neurological function and return to normal life?

4. How important is the availability of surgical resources and skills in the choice of treatment?

Conservative care has traditionally focussed on rest and various procedures aimed at immobilising the affected parts. (Dobson 1951, Griffiths, Seddon \& Roaf, 1956). In the present series no attempt was made to enforce rest. On the contrary mobilisation was encouraged at the earliest possible stage. The focus of conservative care is shifted to supervision of adequate uninterrupted chemotherapy. As a recent writer has put it, referring to Pott's disease in general, 'It is now certain that the vital factor in the effective treatment of the disease is chemotherapy. All other methods of treatment are to be regarded as supplementary to this, not, as has been taught, the other way round.' (Griffiths 1979). Thus the choice is not between conservative treatment, described by one author as 'a policy of "wait and see", , and operative treatment. The choice is between treatment by chemotherapy alone or by chemotherapy supplemented by operative intervention.

Secondly, when if ever, is chemotherapy alone the treatment of choice? The British Medical Journal article referred to above states 'Paraplegia arising during active tuberculous disease may well respond to chemotherapy alone.' The results in the present series support this view. Seventy-five patients $(84 \%)$ recovered sufficiently to walk unaided. All but one of these returned to normal life and 
full activity. Sixty-four patients $(72 \%)$ were completely normal, functionally and neurologically, at the end of follow-up. There were two deaths.

Most recent published series, all of which are either entirely surgical or a combination of surgical and conservative management, report rates of full recovery between $70 \%$ and $84 \%$ (Aguilar, 1968; Ahn, 1967; Ahn, 1976; Bailey et al., 1972; Brasher and Rendleman, 1978; Fowles, 1979; Guirguis, 1967; Hodgson et al., 1964; Hyakumachi, 1976; Jones, 1958; Konstam and Blesovsky, 1962; Kotano, 1976; Martini, 1971; Medical Research Council, 1978; Mizuno et al., 1956; Nisbet, 1954; Paus, 1965; Roper, 1964; Silva, 1978; Suleman, 1969; Tuli, 1975). The overall success rate in the present series is comparable with the best of these results and suggests that there is, at least, a place for conservative management in selected cases.

The third important consideration is the time factor. How long will the patient remain paraplegic? How long will he spend in hospital? How long will it be before he is back to normal activity?

Among the best of recorded results, the series of Hodgson et al. of 1964 showed $37 \%$ recovery of paraplegia in three months as against $47 \%$ in the present series. At six months Hodgson et al's figure is $54 \%$ as against $67 \%$ in the present series. It is often argued that operative decompression produces a more rapid recovery (Konstam 1963). The difference does not appear to be as great as is generally supposed.

In none of the series reviewed by the author did more than half the patients leave hospital in less than six months or more than half the patients return to work and normal life in less than one year from the start of treatment. In the present series, $62 \%$ spent less than six months in hospital and $63 \%$ returned to full activity in less than one year. In terms of recovery of paraplegia, duration of hospital stay and speed of restoration to full activity operative treatment as described in recent literature appears to have little or no advantage over conservative treatment as recorded in this series.

The fourth factor affecting the choice of treatment in Pott's paraplegia is the availability of the skills and resources required for spinal surgery.

The series presented in this paper records the treatment of 89 consecutive cases of Pott's paraplegia in circumstances in which these skills and resources were lacking. The results are comparable with those of other published series both as to speed of recovery and percentage of success. The mortality is low and, while there is one case of recurrent paraplegia in apparently healed disease, there is no case of recurrence of active tuberculous disease in the spine during the period of follow-up.

In the present series, the rationale of treatment was based on the conviction that in the treatment of Pott's paraplegia chemotherapy is fundamental; all other measures supplementary. The decision whether and when to operate will doubtless be affected by the circumstances under which work is carried out. The results of this series suggest that many patients with Pott's paraplegia can be treated as effectively without operation as with.

\section{Acknowledgements}

The author wishes to express his gratitude to the members of the Medical 
Research Council Working Party on Tuberculosis of the Spine for their encouragement and advice throughout the period covered by this series and for permission to include 37 patients who appear in the second series of Masan patients of the Medical Research Council controlled clinical trials of the treatment of spinal tuberculosis.

He also wishes to thank Dr Oh Jung Kun, Superintendent of the National Tuberculosis Hospital, Masan and the authorities of the Korean Ministry of Health whose support made the work possible. Mr D. Ll Griffiths, FRCS, gave valuable advice during the treatment of the patients and the preparation of this paper and the author wishes to acknowledge his gratitude for the encouragement and assistance of this.

Thanks are due to the staff of the laboratory and radiology departments of the National Tuberculosis Hospital for their willing cooperation in work, over and above their normal work load. Appreciation is particularly due to the fourteen members of staff of the Bone and Joint Tuberculosis Unit at Masan whose cheerfulness and willingness to go the second mile first encouraged many a despondent patient to hope that recovery was possible.

The valuable assistance of Miss Margaret Dines and Mrs Selene Wee in typing the manuscripts is gratefully acknowledged.

\section{Résumé}

Les résultats du traitement de 89 cas consécutifs de paraplégie de Pott traités en Coree font l'objet de ce rapport. 85 patients recurent le traitement non opératoire. Quatre patients furent soumis a une transversectomie costale, trois d'entre eux à un stade avancé du traitement, mais sans amélioration apparente. Tous les patients furent suivis pendant plus d'une année, 22 d'entre eux $(22 \%)$ pendant cinq ans ou plus longtemps.

75 patients $\left(84^{\circ}{ }_{0}\right)$ furent rétablis suffisament pour pouvoir marcher sans aide, 74 patients $(83 \%)$ ont repris une vie normale et pleinement active. 64 d'entre eux $\left(72^{\circ}{ }_{0}\right)$ avaient des fonctions neurologiques complètement normales, et, à la fin de la période de contrôle, les autres 10 patients $\left(11^{\circ}{ }_{0}\right)$ avaient encore quelques symptômes neurologiques minimes, sans que leur vie ou leur activité en soient affectées. 54 patients $\left(61^{\circ}{ }_{0}\right)$ ont passé moins de six mois a l'hôpital et $56\left(63^{\circ}\right)$ ont repris une activité normale moins d'une année après le début du traitement. Il y eut deux décès. L'etat neurologique de 41 patients $\left(46^{\circ}{ }_{0}\right)$ s'est déterioré pendant les deux premiers mois de traitement, mais 37 d'entre eux se sont complètement rétablis.

L'importance de la chémothérapie comme base du traitement de la tuberculose de la colonne vertébrale est soulignée. Une comparaison est faite avec les résultats publiés dans d'autres rapports. La place de l'intervention opératoire est discutée et l'on se demande si la nécessité d'une intervention chirurgicale urgente pour le traitement de la paraplégie de la colonne n'a pas été exagérée.

\section{Zusammenfassung}

Das Ergebnis der Behandlung von 89 aufeinanderfolgenden Fällen der Pott'schen Paraplegia, die in Korea zur Behandlung aufgenommen wurden, lautet folgendermassen: 85 Patienten wurden ohne Operation behandelt. Vier Patienten unterzogen sich der Costo-Transversektomy, wobei drei von ihnen in dem späteren Stadium der Behandlung ohne sichtbaren Erfolg blieben. Alle Patienten standen mehr als ein Jahr unter Kontrolle, $22\left(25^{\circ}{ }_{0}\right)$ von ihnen wurden fünf und mehr Jahre beobachtet.

75 Patienten $\left(84^{\circ}{ }_{0}\right)$ wurden ausreichend wiederhergestellt, sodass sie ohne Hilfe gehen konnten. 74 Patienten $(83 \%)$ kehrten zum normalen Leben mit voller Betätigung zurück. 64 von ihnen $(72 \%)$ waren nervlich und körperlich völlig gesund. Am Ende der Nachuntersuchungen hatten die anderen zehn $\left(11^{\circ}{ }_{0}\right)$ minimale, bleibende neurologische Störungen, welche das Leben oder die Betätigung nicht einschränkten. 54 Patienten $\left(61^{\circ}{ }^{\circ}\right)$ verbrachten weniger als sechs Monate im Spital und 56 $\left(63^{\circ}{ }_{0}\right)$ kehrten innerhalb eines Jahres vom Beginn der Behandlung an zur normalen Beschäftigung zurück. Es gab zwei Tote. Bei 41 Patienten $\left(46^{\circ}{ }_{0}\right)$ verschlechterte sich in den ersten zwei Monaten 
der Behandlung der nervliche Zustand, doch 37 von ihnen wurden völlig wiederhergestellt. Die Bedeutung der Chemotherapy als Basis der Behandlung der Pott'schen Krankheit wird nachdrücklich betont. Ein Vergleich mit veröffentlichten Ergebnissen von anderen Studien wurde angestellt. Die Wichtigkeit des operativen Eingriffes wurde erörtert und es wurde daraug hingewiesen, dass dieMöglichkeit für einen dringlichen, frühen operativen Eingriff in der Pott'schen Paraplegia Behundlung wahrscheinlich überbetont wurde.

\section{References}

Aguilar FN 1968 An evaluation of the surgical equipment of Pott's disease in the Philippines. Proceedings of 2nd Western Pacific Rehabilitation Conference Hong Kong 1968. 428-433.

AHN PH 1967 Treatment for Pott's paraplegia. Journal of Korean Orthopaedic Association 2, No. 1:75-87.

AHN PH 1976 Treatment for Pott's paraplegia: a follow-up study of 90 cases. Paper 99. Proceedings of 5th Congress of Western Pacific Orthoaedic Association, Seoul, Korea 1976.

Bailey HL, Sister Gabriel M, Hodgson AR, et al. 1972 Tuberculosis of the spine in children. Journal of Bone and Joint Surgery 54A:1633-1657.

BRASHEAR HR, ReNDleman DA 1978 Pott's paraplegia. Southern Medical Journal 71, No. 11:1379-1382.

British Medical fournal (Editorial). 1979. Tuberculous paraplegia. 1:1442-1443.

DICKSON, JAS 1967 Spinal tuberculosis in Nigerian children. A review of ambulant treatment. Journal of Bone and Joint Surgery 49B, 682-694.

DoBson J 1951 Tuberculosis of the spine; an analysis of the results of consecutive treatment and of the factors influencing the prognosis. Journal of the Bone and Joint Surgery 33B:517-531.

FowLES JV 1979 Tuberculous paraplegia. British Medical Journal 2:500.

Griffiths DLl, Seddon HJ, RoAf R 1956 Pott's Paraplegia. Oxford University Press.

GRIFFITHS DLl 1979 The treatment of spinal tuberculosis. Recent Advances in Orthopaedics No. 3 Chapter 1. 1-17.

Guirguis AR 1967 Pott's paraplegia. Journal of Bone and Joint Surgery 49B:658-667.

HodGson AR, SKINSNES OK, LEONG CY 1967 The pathogenesis of Pott's paraplegia. Journal of Bone and Joint Surgery 49A:1147-1156.

HODGSON AR, YAU A 1967 Pott's paraplegia: a classification based upon the living pathology. Paraplegia, 5, No. 1:1-16.

Hodgson AR, YAU A, Kwon JS, et al. 1964 A clinical study of 100 consecutive cases of Pott's paraplegia. Clinical Orthopaedics 36:128-150.

HyakUMACHI 1976 Pott's paraplegia; results of 40 operated cases. Paper 94. Proceedings of 5th Congress of Western Pacific Orthopaedic Association. Seoul, Korea 1976.

JoNES BS 1958 Pott's paraplegia in the Nigerian. Journal of Bone and Joint Surgery 40B:16-25.

KEMP H 1976 Tuberculosis of the spine. British Journal of Hospital Medicine, Jan. 1976. 39-48.

KeMP HBS, JACKSON JW, JEREMIAH JD, et al. 1973 Anterior fusion of the spine for infective lesions in adults. Journal of Bone and Joint Surgery 55B:715-734.

Konstam PG 1963 Spinal tuberculosis in Nigeria. Annals of the Royal College of Surgeons of England 32:99-115.

Konstam PG, BlesovsKy A 1962 The ambulant treatment of spinal tuberculosis. British Journal of Surgery 50:26-38.

Konstam PG, Konstam ST 1958 Spinal tuberculosis in Southern Nigeria. Journal of Bone and Joint Surgery 40B:26-32.

Kotani PT 1976 Follow-up study for Pott's paraplegia. Paper 97. Proceedings of 5th Congress of Western Pacific Orthopaedic Association, Seoul, Korea 1976.

MARTIN NS 1970 Tuberculosis of the spine. Journal of Bone and Joint Surgery 52B:613-628.

MARTIN NS 1971 Pott's paraplegia. A report on 120 cases. Journal of Bone and Joint Surgery 53B:596-608.

MARTINI M 1979 Traitement Actuel (1979) de la tuberculose osteo-articulaire. Acta orthop. belg. 1979 45:107-124.

Medical Research Council 1973 A controlled trial of ambulant out-patient treatment and in-patient rest in bed in the management of tuberculosis of the spine in patients on standard chemotherapy. Journal of Bone and Joint Surgery 55B:678-697.

Medical Research Council $1976 \mathrm{~A}$ five-year assessment of controlled trials of in-patient and out-patient treatment and of plaster-of-paris jackets for tuberculosis of the spine in children on standard chemotherapy. Journal of Bone and Joint Surgery 58B:399-411.

Medical Research Council 1978 A controlled trial of anterior spinal fusion and debridement in 
the surgical management of tuberculosis of the spine in patients on standard chemotherapy. Tubercle 59:79-105.

Mizuno S, Kotani P, Ooisi S, et al. 1956 Lateral rachotomy in the treatment of Pott's paraplegia. Osaka City Medical Journal 3:1-27.

Mizuno S, Kaibara M, Simazu A 1963 Etiology of Pott's paraplegia. A survey of operative findings. Journal of Japanese Orthopaedic Surgical Society 1963 30:87-104.

Nicholson RA 1974 Twenty years of bone and joint tuberculosis in Bradford. Journal of Bone and Joint Surgery 56B:760-765.

NisBet NW 1954 Spinal decompression in Pott's paraplegia. Lancet 1954, 2, 303-307.

Paus B 1965 Treatment for Tuberculosis of the spine. Norwegian Monographs on Medical Science. Universites forlaget, Oslo.

ROPER A 1964 Spinal caries and paraplegia. Proceedings of the First Symposium on Rehabilitation in Africa, Kampala 1964. 114-115.

SEDDON HJ 1976 The choice of treatment in Pott's disease. Journal of Bone and Joint Surgery 58B:396-7.

SILVA JF 1978 Review of cases of spinal tuberculosis treated at the University Hospital Kuala Lumpur. Journal of Japanese Orthopaedic Association 52, 721-729.

SpIllane JD (ed) Pott's paraplegia. Tropical Neurology, Oxford University Press, London 1973. 57-62.

SULEMAN SK 1969 An analysis of 100 cases of tuberculosis of the spine in Nairobi, Kenya. East African Medical Journal 46, 619-624.

Tuli SM 1975 Tuberculosis of the Spine. New Delhi and Oxford: IBH Publishing Co.

YAU ACMC, HsU LCS, O'BRIEN JP, et al. 1974 Tuberculous kyphosis. Journal of Bone and Joint Surgery 56A:1419-1434. 